\title{
CRYOGENIC OXYGEN JET RESPONSE TO TRANSVERSE ACOUSTIC EXCITATION WITH THE FIRST TRANSVERSE AND THE FIRST COMBINED LONGITUDINAL-TRANSVERSE MODES
}

\section{J. S. Hardi and M. Oschwald}

\author{
Deutsches Zentrum für Luft- und Raumfahrt (DLR) \\ Institute of Space Propulsion \\ Lampoldshausen, Hardthausen 74239, Germany
}

\begin{abstract}
The intact length of the dense oxygen core from an oxygen-hydrogen shear coaxial rocket injector was measured. The measurements were made in a rectangular rocket combustor with optical access and acoustic forcing. The combustor was operated at chamber pressures of 40 and 60 bar, with either ambient temperature or cryogenic hydrogen. The multielement injection spray is subjected to forced transverse gas oscillations of two different acoustic resonance modes; the first transverse (1T) mode at $4200 \mathrm{~Hz}$ and the first combined longitudinal-transverse (1L1T) at $5500 \mathrm{~Hz}$. Intact core length is measured from high-speed shadowgraph imaging. The dependence of intact core length with increasing acoustic amplitude is compared for the two modes of excitation.
\end{abstract}

\section{INTRODUCTION}

A well-known problem faced by designers of liquid propellant rocket engines (LPREs) is the occurrence of self-sustaining oscillations in chamber pressure. The pressure oscillations may be organized in such a way that they take on the form and frequency of acoustic resonance modes of the combustion chamber volume. The transverse modes, with gas oscillations across the face of the injector, are usually favoured. They become self-sustaining by efficiently transferring energy from the reacting propellants to the acoustic field, quickly allowing growth to very high amplitudes which may jeopardise the lifespan of the engine $[1,2]$.

This problem, usually referred to as high-frequency (HF) combustion instability, has, from a scientific standpoint, not yet been solved. Engine designers often 
employ passive damping measures to extract acoustic energy from the combustion chamber and, thereby, suppress HF instability. Such measures allow engines to fly; however, this engineering approach to the problem has proven its fallibility. In Europe, for example, an Ariane 1 launcher was famously struck by an instance of HF instability in one of its Viking engines. Episodes of HF instability have also occurred during testing of the cryogenic, upper-stage HM7B engine for the Ariane 4 vehicle [3], which uses the liquid oxygen/hydrogen $\left(\mathrm{LOx} / \mathrm{H}_{2}\right)$ propellant combination. At subscale, a research combustor at DLR Lampoldshausen known as L42-BKD experiences HF instabilities which initiate spontaneously under certain operating conditions $[4,5]$. The mechanisms by which energy from combustion is transferred to the acoustic field and allow these instabilities become self-sustaining need to be better understood in order to reliably prevent their occurrence.

In LPREs running with $\mathrm{LOx} / \mathrm{H}_{2}$, the use of shear-coaxial type elements in the injector assembly is common. Each element injects a central jet of dense cryogenic LOx and a surrounding high-speed jet of supercritical $\mathrm{H}_{2}$. The dense 'core' of injected LOx penetrates into the combustion chamber and is broken up and atomized by the shear forces exerted by the surrounding $\mathrm{H}_{2}$ flow. Numerous researchers have investigated the breakup behavior experimentally using backlitshadowgraph imaging techniques [6-8]. Others have characterized the breakup behaviors into regimes based on injection parameters [9-11].

The distance the LOx core penetrates into the combustion chamber before being atomized is thought to be important to the coupling of acoustic disturbances with combustion. A measure of this penetration distance is often taken as the axial length of the intact part of the LOx core, from injection to the first complete break in the core. Woodward et al. [12], Yang et al. [13], and Locke et al. [14], for example, have made systematic measurements of the intact core length in lab-scale, shear-coaxial, single-injector combustors burning $\mathrm{LOx} / \mathrm{H}_{2}$.

Of particular relevance to acoustic coupling is the behavior of the LOx core in response to conditions of HF instabilities. Under cold-flow conditions, HF instability has been simulated by forcing a transverse acoustic field using loud speakers. Miesse showed simple jets of water contracting when subjected to oscillating transverse acoustic velocity [15]. A research group at Air Force Research Laboratory in the U.S. has conducted extensive testing with cryogenic liquid nitrogen/gaseous nitrogen as $\mathrm{LOx} / \mathrm{H}_{2}$ simulants, subjected to acoustic forcing. Core length reduction in response to the transverse acoustic velocity was found to be dependent on chamber pressure as well as injection parameters such as gas/liquid velocity ratio (VR) and momentum flux ratio $(J)$ [16-18].

In France and Germany, two-dimensional (2D) combustor designs with optical access have allowed the response of reacting injection sprays to be studied. Under hot-fire conditions, modulating the exhaust nozzle flow rate using a toothed wheel, or siren, has proven to be an effective means of exciting transverse acoustic resonance modes of the combustion chamber. Rey et 
al. [19], Richecoeur et al. [20,21], and Méry et al. [22] have studied LOx/ $\mathrm{H}_{2}$ and $\mathrm{LOx} / \mathrm{CH}_{4}$ response from multiple shear-coaxial injection elements. Valuable observations were made from high-speed imaging of both the flame luminosity and the LOx core. The flame was imaged by capturing filtered chemiluminescent emission from the hydroxyl radical $\left(\mathrm{OH}^{*}\right)$, and the LOx core was visualized using a backlit shadowgraph technique. No measurements of the intact length of the LOx core were presented. Sliphorst applied the same imaging techniques to a single $\mathrm{LOx} / \mathrm{CH}_{4}$ injector and made systematic core length measurements [23]. However, external acoustic forcing was not found to have a measurable influence on the core length, which was attributed to the relatively low acoustic amplitudes.

Measurements of the intact core length with increasing transverse acoustic amplitude were presented by Hardi et al. [24,25]. The measurements were made in a $2 \mathrm{D}$ multielement $\mathrm{LOx} / \mathrm{H}_{2}$ combustor with optical access and siren forcing, known as 'BKH.' High-speed images show significant reduction in core length during excitation of the $1 \mathrm{~T}$ mode of the combustion chamber. The core length is found to be dependent on the amplitude of the oscillating transverse acoustic flow, with a core length reduction of up to $75 \%$ for amplitudes approaching those of naturally occurring HF combustion instabilities. Furthermore, a change in the nature of the core breakup and atomization mechanism was observed.

These previous studies with BKH were made using excitation of the $1 \mathrm{~T}$ mode, around $4200 \mathrm{~Hz}$. This is close to the 1T frequency in real, upper-stage engines. BKH was deliberately designed with this $1 \mathrm{~T}$-mode trait so as to result in spray-acoustic interaction at representative time scales. However, the aforementioned L42-BKD combustor experiences spontaneous instabilities with 1T-mode frequencies above $10 \mathrm{kHz}$. Therefore, the current paper aims to explore the influence of excitation frequency on the core length response.

Core length measurements from BKH during 1T-mode excitation will be compared with those during excitation of the 1L1T mode. The $1 \mathrm{~L} 1 \mathrm{~T}$ mode also produces strong transverse acoustic velocity oscillations at the injector, yet has a resonance frequency at least $1000 \mathrm{~Hz}$ higher. BKH operated at conditions that are representative of real engines, which is intended to maximize the relevance of the results in understanding the coupling mechanisms, of full-scale combustion instabilities.

\section{EXPERIMENTAL METHOD}

\subsection{Combustor}

Testing was conducted using the BKH combustor at the European Research and Technology Test Facility P8 for cryogenic rocket engines at DLR Lam- 


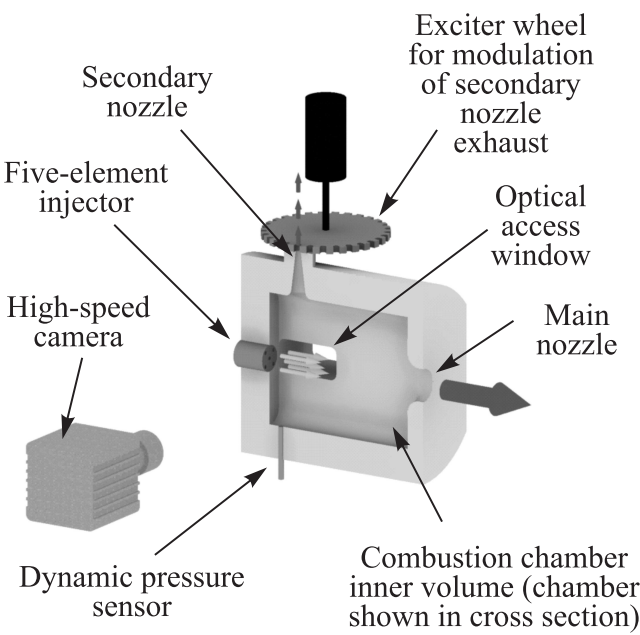

(a)

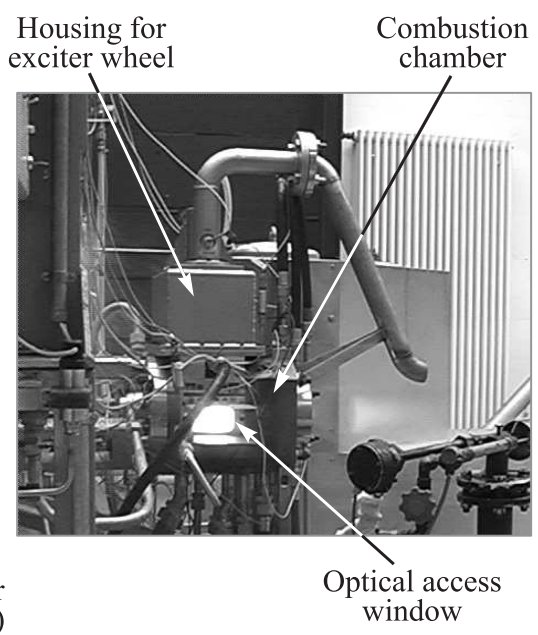

$(b)$

Figure 1 Conceptual illustration of $\mathrm{BKH}(a)$ and a photograph taken during optical testing $(b)$

poldshausen. BKH has a rectangular cross section to fix the excited acoustic resonance frequencies and mode structures and optical access windows for application of high-speed imaging. The injector consists of five shear-coaxial elements arranged in a pattern which provides a representative environment for the central element, surrounded on all sides by other elements. Figure 1 shows BKH illustrated conceptually and photographed during testing with the optical access window clearly visible.

\subsection{Diagnostics}

$\mathrm{BKH}$ uses a suite of conventional, low-frequency diagnostics to specify the operating conditions; fluid temperatures, pressures, and flow rates. A set of six high-frequency Kistler pressure transducers are flush-mounted in the upper and lower combustion chamber walls. These transducers are sampled at $100 \mathrm{kHz}$ and are used for characterizing the acoustic field. Optical access windows provide a viewing area measuring $50 \mathrm{~mm}$ high and $100 \mathrm{~mm}$ long, with one side aligned with the injection plane and the height sufficient to view the entire fiveelement injector. The setup of high-speed cameras is illustrated schematically in Fig. 2.

Backlit shadowgraph images are recorded with a Photron Fastcam SA5 using an RG 850 long pass filter to minimize flame luminosity. Different camera set- 


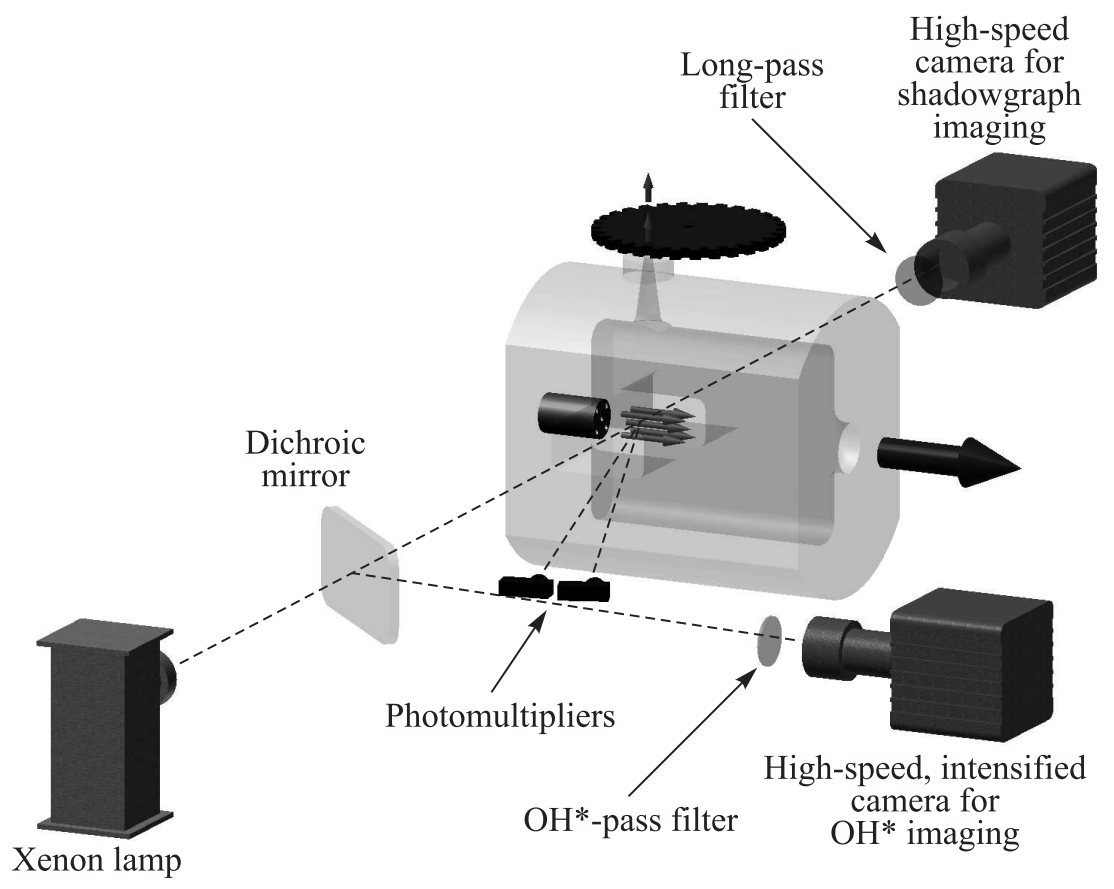

Figure 2 Experimental setup for high-speed optical imaging

tings were used for different tests. Some of the tests were recorded with a frame rate of $7000 \mathrm{fps}$, shutter speed $50 \mu \mathrm{s}$, and pixel resolution $890 \times 445$, while the others had 20,000 fps, shutter speed $33 \mu \mathrm{s}$, and resolution $690 \times 345$. The first set of camera settings results in a sensing resolution of $0.11 \mathrm{~mm}^{2}$ per pixel. The velocity of LOx at the point of injection is around $12 \mathrm{~m} / \mathrm{s}$, resulting in a flow displacement of approximately 5 pixels $(\sim 0.6 \mathrm{~mm})$ during exposure time. The second camera setting gives a sensing resolution of $0.14 \mathrm{~mm}^{2}$ per pixel, resulting in flow displacements of around 3 pixels $(\sim 0.4 \mathrm{~mm})$ during image exposure. This means that the shadowgraph images from both tests may suffer from blurring in some locations. An example of an instantaneous shadowgraph image is shown in Fig. 3.

A dichroic mirror allows a second high-speed camera to simultaneously record $\mathrm{OH}^{*}$ chemiluminescence. For this purpose, a Photron Fastcam-ultima APX-i2 intensified camera with a filter of pass-bandwidth $310 \pm 5 \mathrm{~nm}$ was used to record images with a frame rate of $24,000 \mathrm{fps}$ and resolution of $256 \times 128$ pixels. An example of an instantaneous recorded image, presented in false color, is shown in Fig. 4. Such $\mathrm{OH}^{*}$ emission imaging is taken to indicate the distribution of the reaction zone of the flame. 


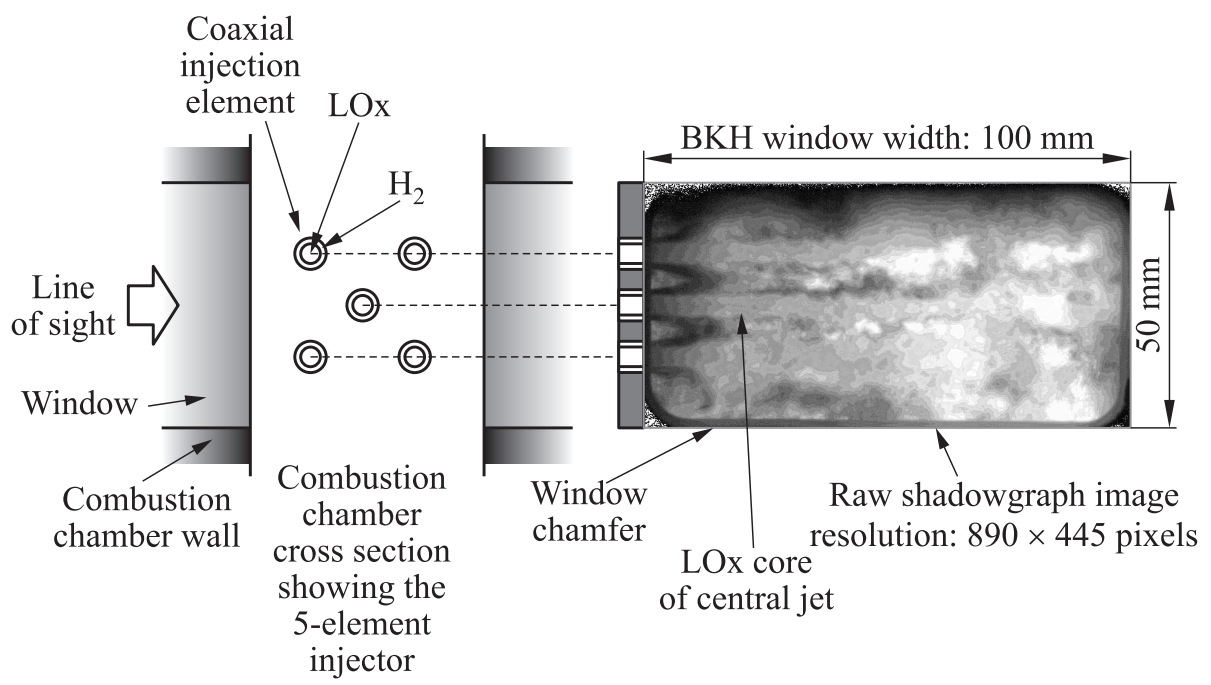

Figure 3 Typical backlit shadowgraph image revealing the structure of the LOx cores

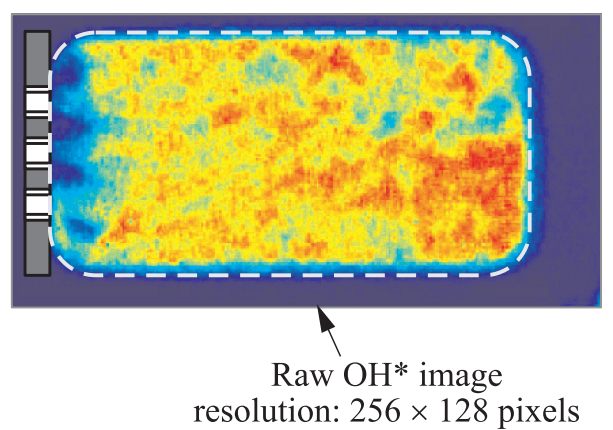

Figure 4 Typical $\mathrm{OH}^{*}$ chemiluminescence image showing the distribution of the reaction zone

\subsection{Operating Conditions}

$\mathrm{BKH}$ operates with injection parameters and mean chamber pressures $\left(P_{\mathrm{cc}}\right)$ which are representative of real, upper-stage LPREs. In this work, imaging results are examined from tests with $P_{\mathrm{cc}}=40$ or 60 bar, using either ambient temperature $(T)$, gaseous hydrogen $\left(\mathrm{GH}_{2}\right)$ or cryogenic, liquid hydrogen $\left(\mathrm{LH}_{2}\right)$, and with an oxidiser-to-fuel ratio (ROF) of 6 . These injection parame- 
Table 1 Operating conditions

\begin{tabular}{|c|c|c|c|c|c|c|c|}
\hline & \multirow{2}{*}{\multicolumn{2}{|c|}{$\begin{array}{c}40 \mathrm{bar} \\
\mathrm{LH}_{2}\end{array}$}} & \multicolumn{5}{|c|}{60 bar } \\
\hline & & & & $\mathrm{GH}_{2}$ & & & \\
\hline & A & $\mathrm{B}$ & $\mathrm{A}$ & $\mathrm{B}$ & $\mathrm{C}$ & $\mathrm{A}$ & $\mathrm{B}$ \\
\hline$P_{\mathrm{cc}}$, bar & 43.5 & 43.5 & 59.7 & 60.3 & 60.5 & 61.3 & 60.3 \\
\hline $\mathrm{ROF}$ & 6.0 & 6.0 & 6.0 & 6.0 & 6.0 & 6.0 & 6.0 \\
\hline$T_{\mathrm{H}}, \mathrm{K}$ & 75 & 62 & 281 & 278 & 288 & 64 & 62 \\
\hline$T_{\mathrm{O}}, \mathrm{K}$ & 132 & 132 & 124 & 128 & 123 & 127 & 126 \\
\hline$\dot{m}, \mathrm{~g} / \mathrm{s}$ & 112 & 112 & 132 & 132 & 132 & 140 & 141 \\
\hline$u_{\mathrm{O}}, \mathrm{m} / \mathrm{s}$ & 11 & 11 & 12 & 12 & 12 & 13 & 13 \\
\hline$u_{\mathrm{H}}, \mathrm{m} / \mathrm{s}$ & 118 & 90 & 423 & 405 & 422 & 84 & 80 \\
\hline VR & 11 & 8.1 & 35 & 33 & 35 & 6.4 & 6.2 \\
\hline$J$ & 1.9 & 1.4 & 6.3 & 5.7 & 6.2 & 1.1 & 1.1 \\
\hline $\operatorname{Re}_{\mathrm{O}}$ & $4.1 \cdot 10^{5}$ & $4.1 \cdot 10^{5}$ & $4.1 \cdot 10^{5}$ & $4.3 \cdot 10^{5}$ & $4.0 \cdot 10^{5}$ & $4.6 \cdot 10^{5}$ & $4.5 \cdot 10^{5}$ \\
\hline $\mathrm{We}_{\mathrm{H}}$ & $1.1 \cdot 10^{5}$ & $7.7 \cdot 10^{5}$ & $8.4 \cdot 10^{5}$ & $7.8 \cdot 10^{5}$ & $8.3 \cdot 10^{5}$ & $1.3 \cdot 10^{5}$ & $1.2 \cdot 10^{5}$ \\
\hline
\end{tabular}

ters corresponding to each operating condition are summarized in Table 1. Other parameters provided are per-element total mass flow rate, $\dot{m}$, and injection velocity, $u$, where the subscripts $\mathrm{O}$ and $\mathrm{H}$ refer to oxygen and hydrogen, respectively. Nondimensional numbers provided are: hydrogen-to-oxygen velocity ratio, $\mathrm{VR}=u_{\mathrm{H}} / u_{\mathrm{O}}$; momentum flux ratio, $J=\left(\rho u^{2}\right)_{\mathrm{H}} /\left(\rho u^{2}\right)_{\mathrm{O}}$; oxygen Reynolds number, $\operatorname{Re}_{\mathrm{O}}=(\rho u D / \mu)_{\mathrm{O}}$ where $D$ is the oxygen injector outlet diameter; and hydrogen Weber number, $\mathrm{We}_{\mathrm{H}}=\rho_{\mathrm{H}}\left(u_{\mathrm{H}}-u_{\mathrm{O}}\right)^{2} D / \sigma_{\mathrm{O}}$. Results from multiple tests running similar conditions are distinguished by the designator $\mathrm{A}, \mathrm{B}$, or $\mathrm{C}$.

\subsection{Acoustic Excitation}

BKH has a main nozzle at the end of the combustion chamber, as well as a secondary nozzle in the upper wall (see Fig. 1). The exhaust flow through the secondary nozzle is modulated with a siren to excite acoustic resonances inside the combustion chamber. The frequency of acoustic excitation is determined by controlling the rotational speed of the siren wheel. By linearly increasing the rotational speed, the excitation frequency is ramped through a desired range between 0 and $6000 \mathrm{~Hz}$ over the course of a 40- to 70-second test firing. The 1T resonance mode of the combustion chamber volume is excited as the excitation frequency passes through approximately $4200 \mathrm{~Hz}$. The 1L1T mode is excited at around $5500 \mathrm{~Hz}$.

The structures of the $1 \mathrm{~T}$ and $1 \mathrm{~L} 1 \mathrm{~T}$ modes, obtained from a numerical modal analysis, are given in Fig. 5. Acoustic pressure distributions are given on the left-hand side, and the corresponding acoustic particle velocity vector field on 

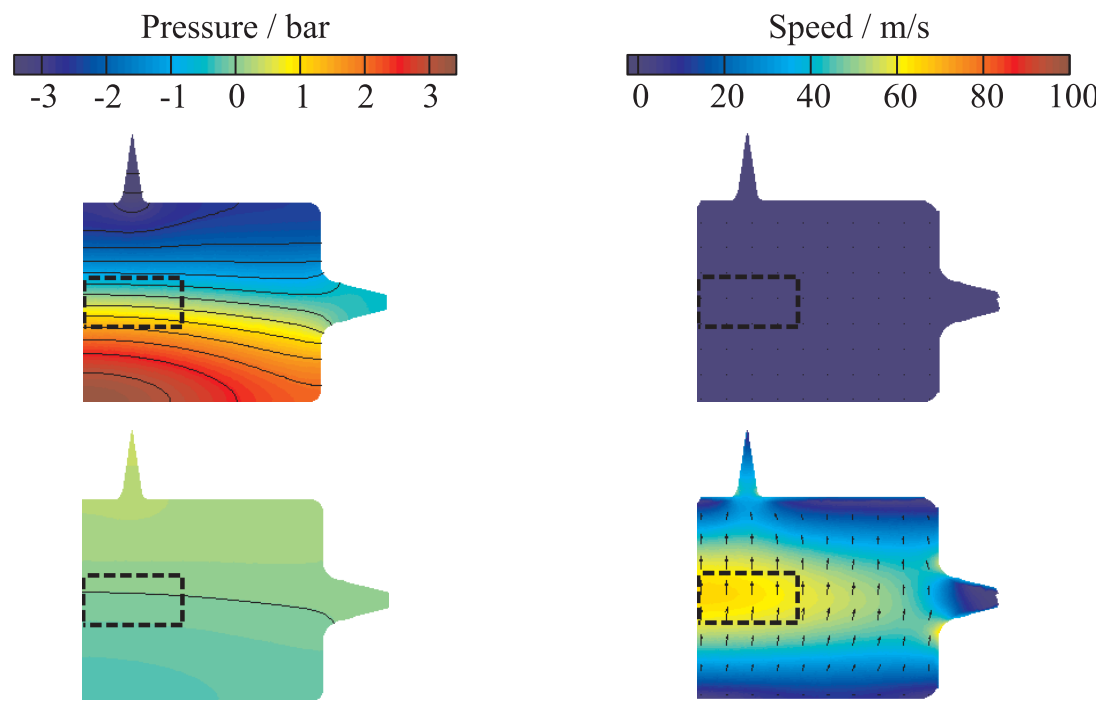

(a)

Pressure / bar
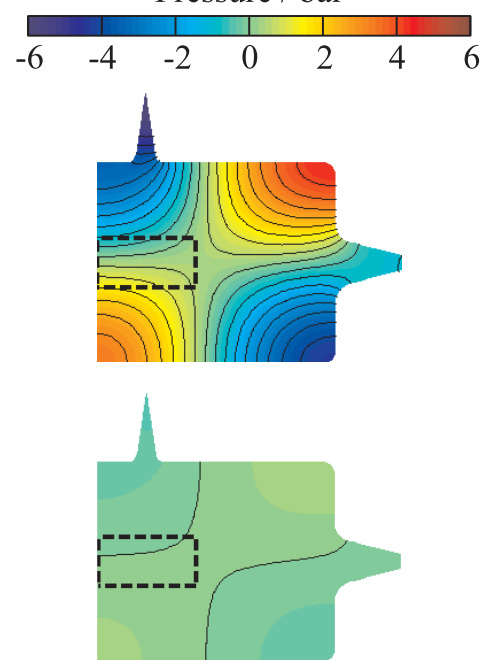

Speed $/ \mathrm{m} / \mathrm{s}$
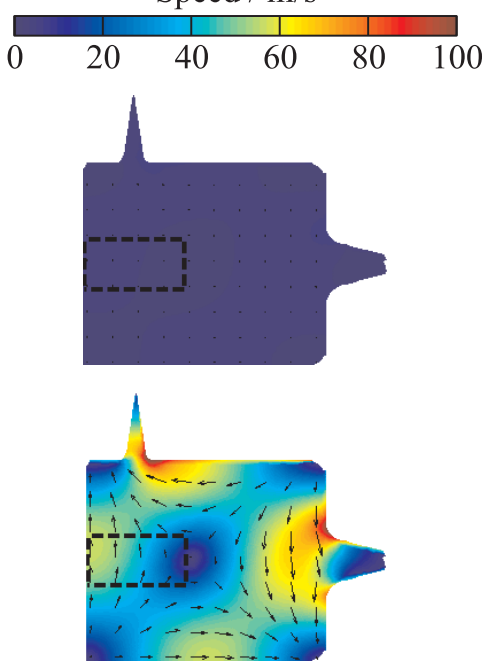

(b)

Figure 5 Acoustic mode shapes of the 1T (a) and 1L1T (b) resonance modes in BKH, showing the pressure distribution (left) and velocity distribution (right). The upper row of each group is at the start of an acoustic cycle and the lower row is one-quarter of a cycle later 
the right. The $1 \mathrm{~T}$ mode (Fig. $5 a$ ) has a pressure node in the near-injector region which means that exciting this mode results in high amplitudes of oscillating acoustic gas motion transverse to the injection axis of the flames. The 1L1T mode (Fig. $5 b$ ) has a similar acoustic field distribution to the $1 \mathrm{~T}$ mode at the location of the injector, also resulting in transverse oscillating gas flow across the injector face. A detailed study of the acoustic characteristics of $\mathrm{BKH}$ was presented by Hardi et al. [26].

Measurements of acoustic amplitude are taken from the dynamic pressure transducer located in the lower wall of the chamber, nearest to the injector face, as indicated in Fig. 1. This sensor is chosen as it is located in a pressure antinode for both the $1 \mathrm{~T}$ and $1 \mathrm{~L} 1 \mathrm{~T}$ modes. High-frequency transducer signals are processed in the following way to obtain a time-dependent estimate of amplitude. First, the signal is high-pass filtered to retain only acoustic resonance content above $2800 \mathrm{~Hz}$. A Butterworth filter was used, employing the filtfilt command in Matlab to prevent any phase shift of the output signal. A sliding root-mean-square (RMS) calculation is performed on the filtered signal, with a mean-window length of 121 samples and 50 percent overlap. Finally, pressure amplitude $p^{\prime}$ is obtained by multiplying the RMS value by the square-root of 2 . From $p^{\prime}$, the magnitude of acoustic velocity $\left(u^{\prime}\right)$ at the nodal line is estimated using $u^{\prime}=\left(c_{\mathrm{bulk}} / \gamma\right)\left(p^{\prime} / P_{\mathrm{cc}}\right)$ where $c_{\mathrm{bulk}}$ is the mean sound speed of the bulk gas mixture in the combustion chamber volume, and $\gamma$ is the ratio of specific heats.

Excitation of the $1 \mathrm{~T}$ and $1 \mathrm{~L} 1 \mathrm{~T}$ resonance modes achieves acoustic pressure amplitudes $\left(p^{\prime}\right)$ of up to $9 \%$ of $P_{\mathrm{cc}}$ ( $18 \%$ peak to peak), as compared to the chamber background noise during off-resonance periods of $p^{\prime} / P_{\mathrm{cc}} \sim 0.9 \%$. Traditionally, an LPRE is considered to experience HF instability when acoustic oscillations reach amplitudes greater than $5 \%$ of $P_{\mathrm{cc}}$ (10\% peak to peak) [27].

\subsection{Liquid Oxygen Core Measurements}

A typical BKH test sequence involves running the combustor to a steady-state operating condition and then accelerating the siren through a range of excitation frequencies so as to meet and excite several acoustic modes of interest. The high-speed cameras are triggered to record for 1- to 4-second durations, as the excitation frequency approaches and passes through peak resonance of the $1 \mathrm{~T}$ and 1L1T modes.

Sample periods of 5 -millisecond duration were selected for various $p^{\prime}$ levels throughout this recording time. Samples were chosen from periods where fluctuations in $p^{\prime}$ were minimal. Sampled image sequences consist of 35 and 100 frames for the 7,000 and 20,000 fps recordings, respectively. Although the excitation frequency is continuously increased at $166 \mathrm{~Hz} / \mathrm{s}$, over a 5-millisecond sample period it can be considered quasi-steady. 


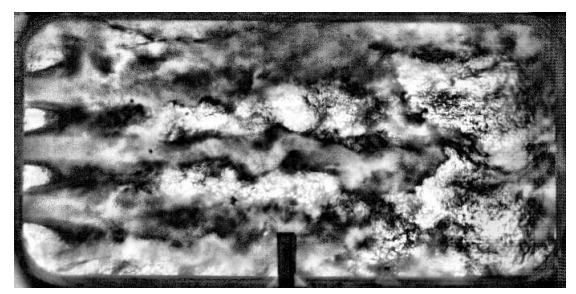

(a)

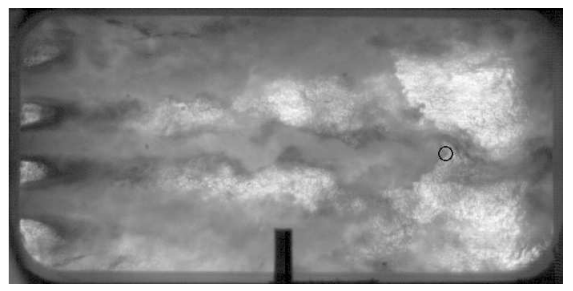

(b)

Figure 6 Example LOx core measurement, showing the contrast-enhanced image (a) and the manually identified end-point location overlaid on the raw image $(b)$

Flow field turbulence, as well as insufficient contrast in the raw shadowgraph images, prohibited successful implementation of an automated routine to detect and trace the intact LOx core. Instead, frame-by-frame identification of the end point of the intact core was performed manually. The images were first processed to enhance contrast gradients and reduce noise to aid the operator in identifying the core end point. Figure 6 shows an example frame where the end-point location has been identified in the raw image with the assistance of the contrast-enhanced image.

\section{RESULTS}

\subsection{Without Acoustic Excitation}

First, the qualitative character of the shadowgraph image in Fig. 3 is considered, taken from the 60 -bar $\mathrm{GH}_{2}$ test $\mathrm{A}$. As this image was taken during off-resonance excitation with very low acoustic amplitudes, it is considered to represent the natural behavior of the injected spray flame. The dense LOx core of the central injection jet and those of the nearest outer (upper and lower) elements are clearly visible. They are identifiable by the light shade of grey which masks the surface of the dense LOx structures. This shade of grey is near-infrared emission from hot combustion products $\left(\mathrm{H}_{2} \mathrm{O}\right)$ forming in the thin shear layer between the surface of the $\mathrm{LOx}$ core and the surrounding $\mathrm{H}_{2}$ where primary mixing and reaction takes place. The presence of infrared emission in the image is the result of the longer exposure time required to compensate for the lower intensity of a continuous backlighting source. A similar effect of this compromise was experienced by Locke et al. [14].

While the outer LOx jets deflect outwards somewhat, the central LOx jet appears to continue more or less axially, as would be expected inside a real engine. The outer four injectors appear to have served their somewhat sacrificial purpose 
of providing a representative environment for the central injector. Dynamic behavior of the central LOx core is observed in the high-speed image sequences. The central core penetrates a distance of approximately $13 L / D$ into the chamber before beginning to breakup, where $L$ is the intact core length and $D$ is the diameter of the LOx injector $-3.5 \mathrm{~mm}$. The breakup mechanism is one of successive detachments of large, dense oxygen structures which become entrained in the axial mean flow. A detailed description of this natural shedding behavior, as well as example image sequences, can be found in $[24,25]$.

\subsection{With Acoustic Excitation}

Figure 7 shows example frames during 1T-mode excitation in 60 -bar $\mathrm{GH}_{2}$ test $\mathrm{C}$. Here, the central LOx core length is greatly reduced compared to its natural state, now only extending around $7 L / D$ downstream of injection. The core is no longer given the opportunity to develop downstream because each pass of the transverse acoustic wave strips material from its surface. The core breakup mechanism has changed from its natural axial shedding mode to the one of stripping and entrainment in the oscillating transverse flow. Again, this behavior is described in more detail in $[24,25]$.

Cold flow experiments [28] and three-dimensional numerical modeling [29-31] of jet-acoustic interaction have revealed further details of the core response. The jet is observed to flatten into a sheet in the plane perpendicular to the impinging acoustic wave. This explains the flattening tapered form of the intact part of the LOx core when viewed from the side. This deformation results from the mean pressure gradient distribution which develops around the jet circumference when exposed to a continuously oscillating gas flow. Viewing this flattening from above (or the wave impingement direction) is currently only possible in cold flow experiments and numerical simulations since in hot-fire experiments, the interaction has so far only been observed from the side.

Shortening of the LOx cores is accompanied by a retraction of the flame towards the injection plane. The instantaneous $\mathrm{OH}^{*}$ images in Fig. 7 (lower
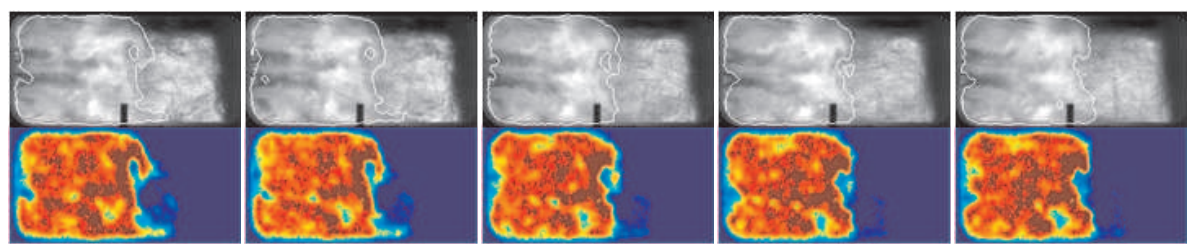

Figure 7 Example shadowgraph and $\mathrm{OH}^{*}$ image sequence during 1T-mode excitation 
row) shows that the reaction zone is no longer well distributed as the LOx core travels downstream; rather, there are compact regions of high emission intensity as all combustion is taking place in a space approximately half the length of the window $(50 \mathrm{~mm})$. Core shortening and corresponding change in flame structure to a more compact, intense form has also been observed with $\mathrm{LOx} / \mathrm{CH}_{4}[20-22]$. This demonstrates the importance of characterizing the response of the $\mathrm{LOx}$ cores to transverse acoustic oscillations, since redistribution of heat release in the chamber will affect the coupling mechanism driving HF instability.

\subsection{Comparison of Response to the First Transverse and the First Combined Longitudinal-Transverse Modes}

Transverse acoustic atomization appears not to be as effective for the 1L1T mode as for the $1 \mathrm{~T}$ mode. Figure 8 shows a comparison of instantaneous core length measurements for the $1 \mathrm{~T}$ and 1L1T modes. Two sets of measurements at different operating conditions are presented, each set for the same acoustic amplitude. In both examples, the core is longer during 1L1T-mode excitation. Its structure appears more sinuous, as if the transition from the natural breakup mechanism (for low acoustic amplitudes) to the transverse stripping mechanism (at higher amplitudes) is not as advanced.
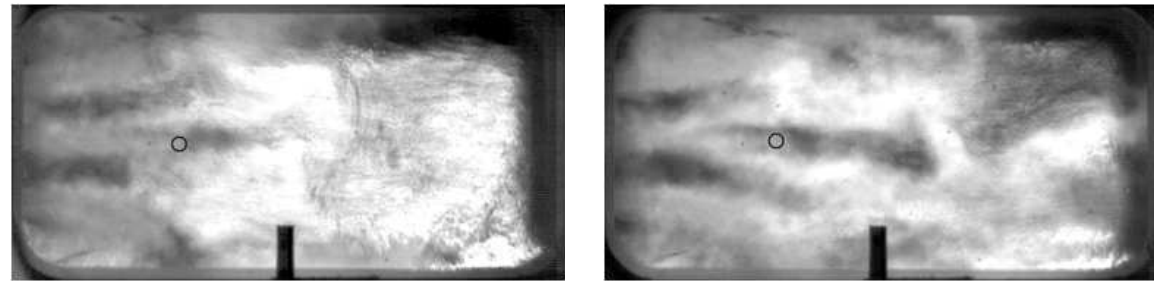

(a)
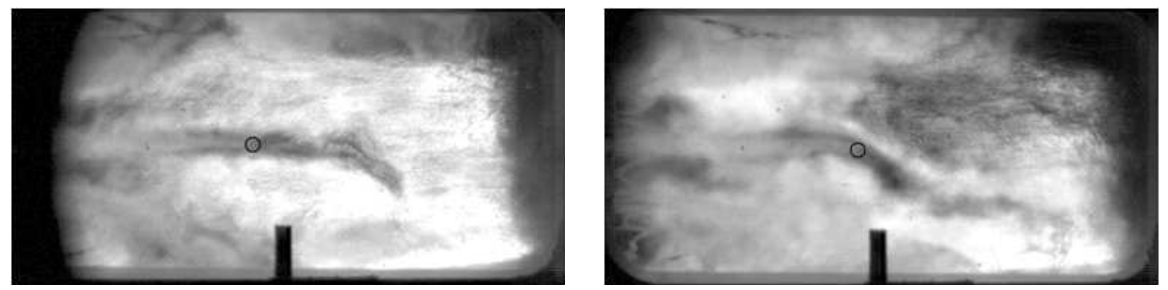

(b)

Figure 8 Comparison of instantaneous core length measurements for $1 \mathrm{~T}(a)$ and 1L1T $(b)$ modes, for the same acoustic amplitude: left column $-p^{\prime} / P_{\mathrm{cc}}=6.7 \%$, 40 bar, $\mathrm{LH}_{2}$ test $\mathrm{B}(a)$ and test $\mathrm{A}(b)$; and right column $-p^{\prime} / P_{\mathrm{cc}}=5.5 \%, 60$ bar, $\mathrm{LH}_{2}$ test A 


\subsection{Intact Core Length}

Systematic measurements of intact core length were made during 1L1T-mode excitation, for various levels of acoustic excitation amplitude. These are presented here for comparison with the previous measurements made by the authors $[24,25]$ under 1T-mode excitation. Table 1 lists the complete range of operating conditions covered for all $1 \mathrm{~T}$ and $1 \mathrm{~L} 1 \mathrm{~T}$ measurements.

Figure 9 presents all core length measurements with increasing acoustic amplitude for tests with 60 -bar chamber pressure. A trend line is provided for tests with $\mathrm{GH}_{2}$; it is not a fit to the data, but arbitrarily drawn and provided merely to assist the eye in orienting the many measurement points. Filled symbols are used for 1L1T excitation. These points consistently lie above those for $1 \mathrm{~T}$ excitation, meaning the core length was greater for the same acoustic amplitude, but under a 1L1T-mode distribution and frequency. A second trend line, converging on the same natural core length, is provided for orientation with the $\mathrm{GH}_{2} 1 \mathrm{~L} 1 \mathrm{~T}$ set of points.

Figure 10 presents measurements for 40-bar chamber pressure. Here, the difference between 1T and 1L1T excitations is also clearly evident. Trend lines are again provided for orientation, although the fewer number of measurement points available render their placement even less meaningful. They do, however, appear to converge on a longer natural core length than for the tests at 60 bar.

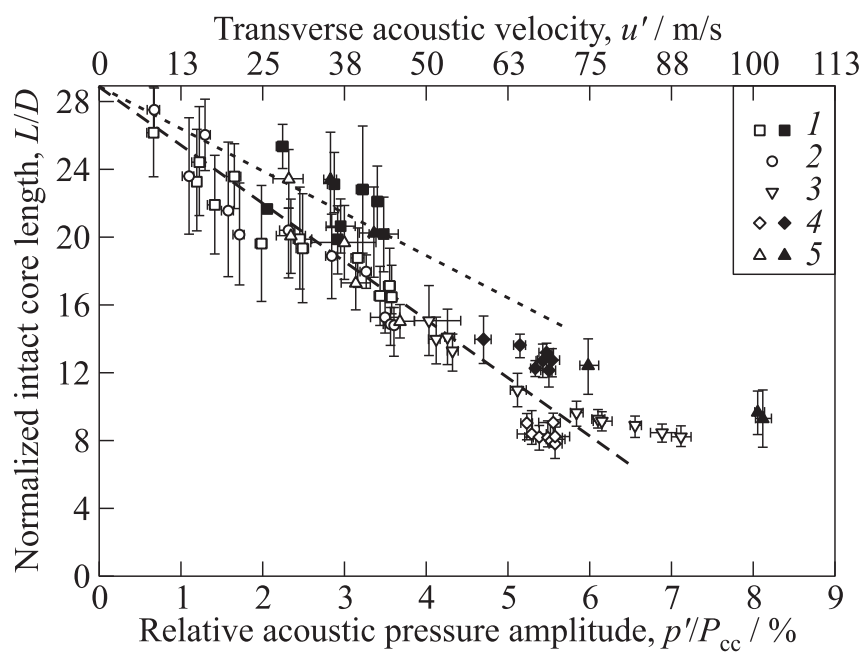

Figure 9 Intact core length measurements under 1T- (empty signs) and 1L1T-mode (filled signs) excitations in tests with $P_{\mathrm{cc}}=60$ bar: $1-\mathrm{GH}_{2}$, test A; $2-\mathrm{GH}_{2}$, test B; $3-\mathrm{GH}_{2}$, test $\mathrm{C} ; 4-\mathrm{LH}_{2}$, test $\mathrm{A} ; 5-\mathrm{LH}_{2}$, test $\mathrm{B}$; and dashed and dotted lines trend lines for all $\mathrm{GH}_{2}$ tests with $1 \mathrm{~T}$ - and 1L1T-mode excitations, respectively 


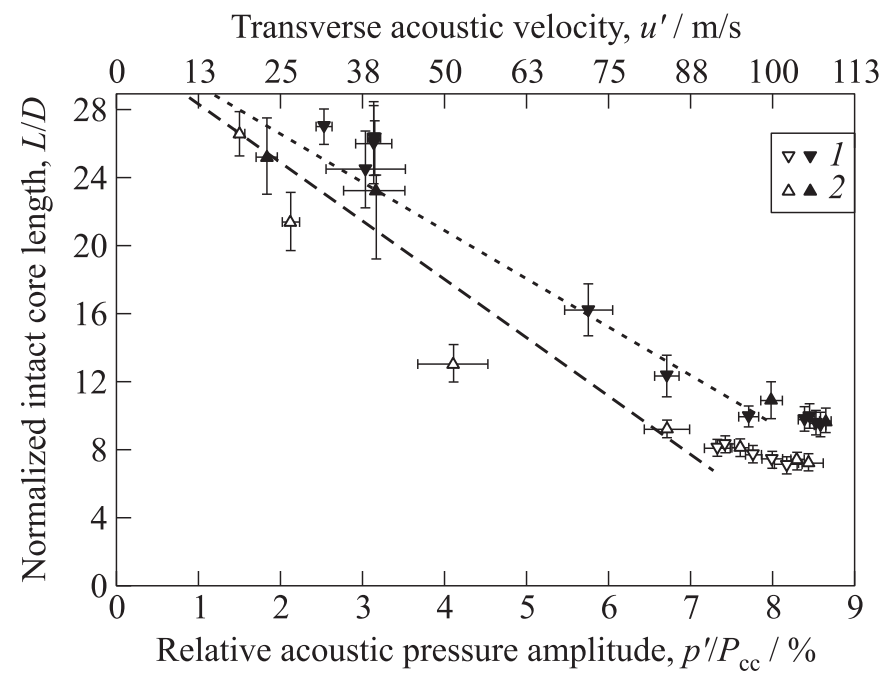

Figure 10 Intact core length measurements under 1T- (empty signs) and 1L1T-mode (filled signs) excitations in tests with $P_{\mathrm{cc}}=40 \mathrm{bar}, \mathrm{LH}_{2}: 1$ - test A; 2 - test $\mathrm{B}$; and dashed and dotted lines - trend lines for tests with 1T- and 1L1T-mode excitations, respectively

In both plots, the vertical error bars reflect fluctuation in core length due to the natural breakup mechanism, with axial growth and detachment. The noticeable reduction in error bar length with increasing acoustic amplitude reflects the transition from this natural breakup to the transverse stripping mechanism.

Scatter in the measurements is due to natural turbulence and bending of the long sinuous core. Bending of the core occasionally gives an artificially short length measurement. Using the integrated length of the core center instead of end point location may reduce the influence of this behavior. However, as discussed previously, the automated core detection and tracing routine was unreliable.

\section{DISCUSSION}

Intact core length results show consistently longer cores for 1L1T-mode excitation. The acoustic field distribution for the 1L1T mode may account for its lesser influence. The $1 \mathrm{~T}$ mode has a near uniform acoustic velocity field along the main chamber axis, corresponding to its pressure nodal line. By nature, the 1L1T mode has a vertical nodal line approximately half way along the chamber axis. This means the amplitude of oscillating acoustic velocity, $u^{\prime}$, changes in the chamber axial direction. From a velocity antinode at the injection plane, it 
decreases to zero at the vertical nodal line, then increases again (with opposing phase) approaching the main nozzle end of the chamber. Figure 11 compares the profiles of the transverse (vertical) component of $u^{\prime}$ along the chamber central axis for the $1 \mathrm{~T}$ and $1 \mathrm{~L} 1 \mathrm{~T}$ modes. The velocity amplitude profiles were extracted from the numerical modal analysis in Fig. 5.

The first $100 \mathrm{~mm}$ of the transverse velocity profiles in Fig. 11 are compared more closely, as this is the region where most jet-acoustic interaction occurs, and where LOx core measurements can still be made. By the end of the optical window, $100 \mathrm{~mm}$ downstream, $u^{\prime}$ is practically zero for the $1 \mathrm{~L} 1 \mathrm{~T}$ mode, while

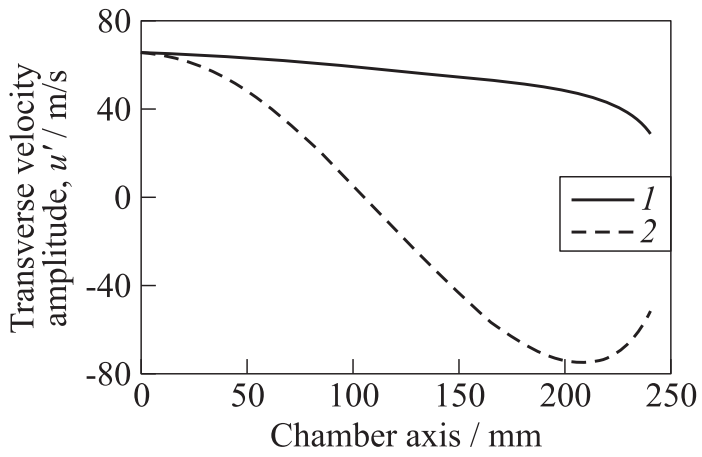

(a)

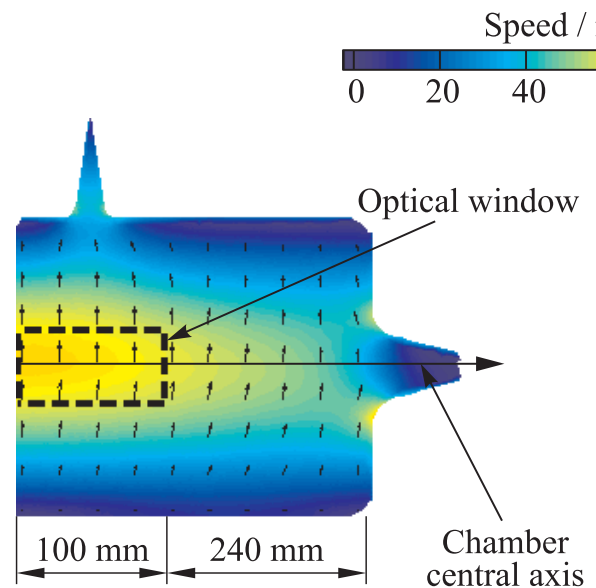

(b)

$80 \quad 100$

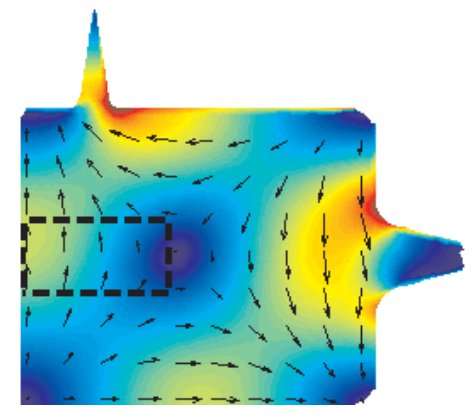

(c)

Figure 11 Transverse velocity amplitude profiles along the chamber central axis for the $1 \mathrm{~T}(1)$ and $1 \mathrm{~L} 1 \mathrm{~T}(2)$ modes $(a)$, and the modal velocity distributions from which they are extracted: $(b) 1 \mathrm{~T}$ mode and $(c) 1 \mathrm{~L} 1 \mathrm{~T}$ mode 
the $1 \mathrm{~T}$ mode is still almost at full strength. The mean value of transverse $u^{\prime}$ from 0 to $100 \mathrm{~mm}$ for the $1 \mathrm{~L} 1 \mathrm{~T}$ mode is $40 \%$ less than that of the $1 \mathrm{~T}$ mode.

Additionally, the different time scales of jet-acoustic interaction may contribute to the difference in $1 \mathrm{~T}$ and $1 \mathrm{~L} 1 \mathrm{~T}$ modes response. The time scale of acoustic interaction with a jet is often compared to the convective time scale using the Strouhal number (St). Preferred modes of interaction for round jets usually occur in the St range 0.2 to $0.4[32,33]$. This has been demonstrated, for example, with unsteady Reynolds-averaged Navier-Stokes simulations of velocity oscillations on a cryogenic nitrogen jet [29]. The peak response, with the most shortening, was for St values from 0.2 to 0.3 , above which the jet length increased again. Schmitt et al. [34] compared St values for unexcited and excited cryogenic nitrogen jets. Natural jet instability frequencies were measured from large-eddy simulations, and the corresponding St values compared to those defined by the acoustic forcing in an accompanying experiment. The greater the difference between the natural and excited St values, the lower the level of jet response, both in experiment and simulation.

Here, it is instructive to consider the time scales of jet-acoustic interaction in BKH by comparing St values for 1T- and 1L1T-mode excitations. Excited Strouhal numbers can be calculated using the mean excitation frequency, $f_{\text {ex }}$, applied during high-speed imaging for the core length measurements in this work. Excited St values are given by $\mathrm{St}_{\mathrm{ex}}^{1 \mathrm{~T}}=f_{\mathrm{ex}}^{1 \mathrm{~T}} D / u_{\mathrm{O}}$ for $1 \mathrm{~T}$-mode excitation, or $\mathrm{St}_{\mathrm{ex}}^{1 \mathrm{~L} 1 \mathrm{~T}}=f_{\mathrm{ex}}^{1 \mathrm{~L} 1 \mathrm{~T}} D / u_{\mathrm{O}}$ for the $1 \mathrm{~L} 1 \mathrm{~T}$ mode. Results are summarized in Table 2. All $\mathrm{St}_{\mathrm{ex}}$ for the BKH tests are high, between 1.1 and 1.7, suggesting inefficient interaction with the acoustic field; a property which is no doubt advantageous for the stability of operational engines. Values for 1L1T-mode excitation, $\mathrm{St}_{\mathrm{ex}}^{1 \mathrm{~L} 1 \mathrm{~T}}$, are higher than those for $1 \mathrm{~T}$ excitation, and even farther from the usual range for preferred jet modes (0.2 to 0.4). Physically, this difference in $\mathrm{St}_{\text {ex }}$ expresses the shorter duration over which the $1 \mathrm{~L} 1 \mathrm{~T}$ wave exerts influence on the LOx core in each acoustic cycle. Thus, the transverse stripping mechanism may not be as effective for the 1L1T mode as for the lower frequency $1 \mathrm{~T}$ mode.

Table 2 Strouhal numbers for operating conditions with acoustic excitation

\begin{tabular}{lccccccc}
\hline & \multicolumn{2}{c}{40 bar } & \multicolumn{3}{c}{60 bar } \\
\cline { 2 - 8 } & \multicolumn{2}{c}{$\mathrm{LH}_{2}$} & $\mathrm{GH}$ & & \multicolumn{2}{c}{$\mathrm{LH}_{2}$} \\
\cline { 2 - 8 } & $\mathrm{A}$ & $\mathrm{B}$ & $\mathrm{A}$ & $\mathrm{B}$ & $\mathrm{C}$ & $\mathrm{A}$ & $\mathrm{B}$ \\
\hline$f_{\mathrm{ex}}^{1 \mathrm{~T}}, \mathrm{~Hz}$ & 4350 & 4330 & 4370 & 4380 & 4360 & 4240 & 4300 \\
$\mathrm{St}_{\mathrm{ex}}^{1 \mathrm{~T}}$ & 1.4 & 1.4 & 1.3 & 1.3 & 1.3 & 1.1 & 1.2 \\
$f_{\text {ex }}^{1 \mathrm{~L} 1 \mathrm{~T}}, \mathrm{~Hz}$ & & 5450 & 5470 & & & & 5430 \\
$\mathrm{St}_{\mathrm{ex}}^{1 \mathrm{~L} 1 \mathrm{~T}}$ & & 1.7 & 1.6 & & & & 1.5 \\
\hline
\end{tabular}


The goal of this study was to resolve such influence of frequency on LOx core breakup. However, in the current BKH configuration, the influence of frequency cannot be distinguished from that of the different mode shapes. It appears likely that the difference in modal velocity distributions is mostly responsible for the difference in LOx core length. Nevertheless, the experimental measurements presented here would be well suited for the quantitative validation of numerical models, particularly, their ability to capture the response to different acoustic field distributions.

The question of frequency dependence of the transverse acoustic atomization mechanism remains. It will determine the applicability of results from research combustors such as BKH to the modeling of other unstable combustors, for example, BKD. While BKH and BKD have a similar injector element, in both design and scale, BKD has different dominant frequencies of 1T-mode instability. Any frequency dependence of intact core length should be taken into account, as the distribution of energy release is also affected.

\section{CONCLUDING REMARKS}

The rectangular rocket combustor BKH was operated at conditions representative of real upper-stage engines. High-speed backlit shadowgraph images were used to measure the length of the intact LOx core from the central element of the five-element shear-coaxial injector. Acoustic forcing was used to excite the chamber $1 \mathrm{~T}$ and $1 \mathrm{~L} 1 \mathrm{~T}$ resonance modes to amplitudes representative of real HF combustion instabilities. Exciting these modes subjects the injected propellant streams to oscillating transverse acoustic gas motion. The core length decreases with increasing acoustic amplitude, and the mechanism of core breakup changes.

Core lengths under 1L1T-mode excitation were consistently greater than for the $1 \mathrm{~T}$ mode. This is thought to be due primarily to the modal velocity distribution of the 1L1T mode, resulting in overall lower transverse velocity amplitudes incident on the LOx core.

The higher frequency of the 1L1T mode provides less time for each passing wave to interact with the core. This may contribute to the greater core lengths under 1L1T-mode excitation. The range of Strouhal number values under excitation in BKH suggests unfavourable conditions for the acoustic disturbance to influence the core, especially for the $1 \mathrm{~L} 1 \mathrm{~T}$ mode. However, any frequency dependence of the transverse atomization mechanism could not be resolved from the influence of the modal velocity distribution.

Nevertheless, any such frequency dependence should be taken into account when attempting to exploit core length measurements in modeling combustion instabilities. Measurements made in one system may not be applicable to another where the instability has a different dominant frequency. 
Changing core length was observed to change the extent of the flame and, thus, the distribution of heat release in the combustion chamber. This undoubtedly plays a role in the coupling of unsteady heat release with acoustics in unstable rocket engines. Therefore, LOx core measurements are important in understanding the driving mechanisms of $\mathrm{HF}$ instabilities.

\section{ACKNOWLEDGMENTS}

The Authors are grateful to the crew of the P8 test bench as well as Dmitry Suslov and Philipp Gross for their professional efforts in test operations. Many thanks also to Walter Clauß for design and operation of optical diagnostics and to Scott Beinke for assistance with analysis.

\section{REFERENCES}

1. Harrje, D. T. 1972. Historical survey. Liquid propellant rocket combustion instability. Eds. D. T. Harrje and F. H. Reardon. Washington, DC, USA: NASA. 30-34.

2. Culick, F.E.C., and V. Yang. 1995. Overview of combustion instabilities in liquid-propellant rocket engines. Liquid rocket engine combustion instability. Eds. V. Yang and W. E. Anderson. Progress in astronautics and aeronautics ser. Reston, VA: AIAA. 169:3-37. doi: 10.2514/5.9781600866371.0003.0037.

3. Preclik, D., and P. Spagna. 1989. Low frequency and high frequency combustion oscillation phenomena inside a rocket combustion chamber fed by liquid or gaseous propellants. AGARD Conference Proceedings. 450.

4. Gröning, S., M. Oschwald, and T. Sattelmayer. 2012. Selbst erregte tangentiale Moden in einer Raketenbrennkammer unter repräsentativen Bedingungen. Deutscher Luft- und Raumfahrtkongress.

5. Gröning, S., D. I. Suslov, M. Oschwald, and T. Sattelmayer. 2013. Stability behaviour of a cylindrical rocket engine combustion chamber operated with liquid hydrogen and liquid oxygen. 5th European Conference for Aeronautics and Space Sciences.

6. Mayer, W., A.H. Schik, B. Vieille, C. Chauveau, I. Gokalp, D. G. Talley, and R. D. Woodward. 1998. Atomization and breakup of cryogenic propellants under high-pressure subcritical and supercritical conditions. J. Propul. Power 14(5):835842 .

7. Juniper, M., A. Tripathi, P. Scouflaire, J. C. Rolon, and S. Candel. 2000. Structure of cryogenic flames at elevated pressures. Proc. Combust. Inst. 28:1103-1109.

8. Chehroudi, B., D. Talley, W. Mayer, R. Branam, J. J. Smith, A.H. Schik, and M. Oschwald. 2003. Understanding injection into high pressure supercritical environments. 5th Symposium (International) on Liquid Space Propulsion.

9. Farago, Z., and N. Chigier. 1992. Morphological classification of disintegration of round jets in a coaxial airstream. Atomization Spray 2:137-153. 
10. Chigier, N., and R. D. Reitz. 1995. Regimes of jet breakup and breakup mechanisms (physical aspects). Recent advances in spray combustion: Spray atomization and droplet burning phenomena. Ed. K. Kuo. New York, NY, USA: AIAA. 166:109-136.

11. Lasheras, J., and E. Hopfinger. 2000. Liquid jet instability and atomization in a coaxial gas stream. Ann. Rev. Fluid Mech. 1873:275-308.

12. Woodward, R.D., S. Pal, S. Farhangi, and R. J. Santoro. 2006. LOx/GH 2 shear coaxial injector atomization studies at large momentum flux ratios. 42nd AIAA/ASME/SAE/ASEE Joint Propulsion Conference \& Exhibit. 1-20.

13. Yang, B., F. Cuoco, and M. Oschwald. 2007. Atomization and flames in $\mathrm{LOx} / \mathrm{H}_{2^{-}}$ and $\mathrm{LOx} / \mathrm{CH}_{4}$-spray combustion. J. Propul. Power 23(4):763-771.

14. Locke, J. M., S. Pal, R. D. Woodward, and R. J. Santoro. 2010. High speed visualization of $\mathrm{LOx} / \mathrm{GH}_{2}$ rocket injector flowfield: Hot-fire and cold-flow experiments. 46th AIAA/ASME/SAE/ASEE Joint Propulsion Conference \& Exhibit. 1-18.

15. Miesse, C. C. 1955. The effect of ambient pressure oscillations on the disintegration and dispersion of a liquid jet. Jet Propulsion 25(10):525-530. doi: 10.2514/8.6813.

16. Davis, D. W., and B. Chehroudi. 2007. Measurements in an acoustically driven coaxial jet under sub-, near-, and supercritical conditions. J. Propul. Power $23(2): 364-374$.

17. Leyva, I. A., B. Chehroudi, and D. G. Talley. 2007. Dark core analysis of coaxial injectors at sub-, near-, and supercritical pressures in a transverse acoustic field. 43rd AIAA/ASME/SAE/ASEE Joint Propulsion Conference \& Exhibit. 93524.

18. Rodriguez, J. I., J. J. Graham, I. A. Leyva, and D. G. Talley. 2009. Effect of variable phase transverse acoustic fields on coaxial jet forced spread angles. 47th AIAA Aerospace Sciences Meeting. 1-11.

19. Rey, C., S. Ducruix, F. Richecoeur, P. Scouflaire, and S. Candel. 2004. High frequency combustion instabilities associated with collective interactions in liquid propulsion. 40th AIAA/ASME/SAE/ASEE Joint Propulsion Conference \& Exhibit. 1-13.

20. Richecoeur, F. 2006. Expérimentations et simulations numériques des interactions entre modes acoustiques transverses et flammes cryotechniques. Paris, France: École Centrale Paris. PhD Thesis. 74-84.

21. Richecoeur, F., P. Scouflaire, S. Ducruix, and S. Candel. 2006. High frequency transverse acoustic coupling in a multiple injector cryogenic combustor. J. Propul. Power 22(4):790-799.

22. Méry, Y., L. Hakim, P. Scouflaire, L. Vingert, S. Ducruix, and S. Candel. 2013. Experimental investigation of cryogenic flame dynamics under transverse acoustic oscillations. Comp. Rend. Mécanique 341(1-2):100-109.

23. Sliphorst, M. 2011. High frequency combustion instabilities of $\mathrm{LOx} / \mathrm{CH}_{4}$ spray flames in rocket engine combustion chambers. Delft, The Netherlands: Technische Universiteit Delft. M.Sc. Thesis. 107-110. Available at: http://repository.tudelft.nl/ view/ir/uuid\%3A403ca079-82db-4d09-9676-c3b38c007283/ (accessed July 8, 2015).

24. Hardi, J.S. 2012. Experimental investigation of high frequency combustion instability in cryogenic oxygen-hydrogen rocket engines. Adelaide, Australia: The University of Adelaide. PhD Thesis. 164-170. Available at: https://digital.library. adelaide.edu.au/dspace/handle/2440/82071 (accessed July 8, 2015). 
25. Hardi, J. S., H. C. Gomez Martinez, M. Oschwald, and B. B. Dally. 2014. LOx jet atomization under transverse acoustic oscillations. J. Propul. Power 30(2):337-349.

26. Hardi, J. S., M. Oschwald, and B.B. Dally. 2013. Acoustic characterisation of a rectangular rocket combustor with liquid oxygen and hydrogen propellants. J. Aerospace Eng. 227(3):431-441.

27. Fry, R. S., and M. D. Klem. 1997. Guidelines for combustion stability specifications and verification procedures for liquid propellant rocket engines. Chemical Propulsion Information Agency.

28. Baillot, F., J.-B. B. Blaisot, G. Boisdron, and C. Dumouchel. 2009. Behaviour of an air-assisted jet submitted to a transverse high-frequency acoustic field. J. Fluid Mech. 640:305-342.

29. Ribert, G., M. Jarczyk, C. A. Niedermeier, X. Petit, M. Pfitzner, M. Schmid, and T. Sattelmayer. 2011. Supercritical fluid flow injection. Summer Program 2011 Proceedings. Deutsche Forschungsgemeinschaft DFG, Sonderforschungsbereich Transregio. 40.

30. Schmid, M. 2014. Thermoakustische Kopplungsmechanismen in Flüssigkeitsraketentriebwerken. Technische Universität München.

31. Schmitt, T., L. Hakim, M. Boileau, G. Staffelbach, A. Ruiz, S. Ducruix, B. Cuenot, and S. Candel. 2014. Large-eddy simulation of a multiple injector cryogenic combustor under transcritical conditions and large amplitude high frequency modulations. Space Propulsion 2014.

32. Gutmark, E., and C.-M. Ho. 1983. Preferred modes and the spreading rates of jets. Phys. Fluids 26(10):2932-2938.

33. Birbaud, A.-L., D. Durox, S. Ducruix, and S. Candel. 2007. Dynamics of free jets submitted to upstream acoustic modulations. Phys. Fluids 19(1):013602.

34. Schmitt, T., J. I. Rodriguez, I. A. Leyva, and S. Candel. 2012. Experiments and numerical simulation of mixing under supercritical conditions. Phys. Fluids 24(5):055104. 